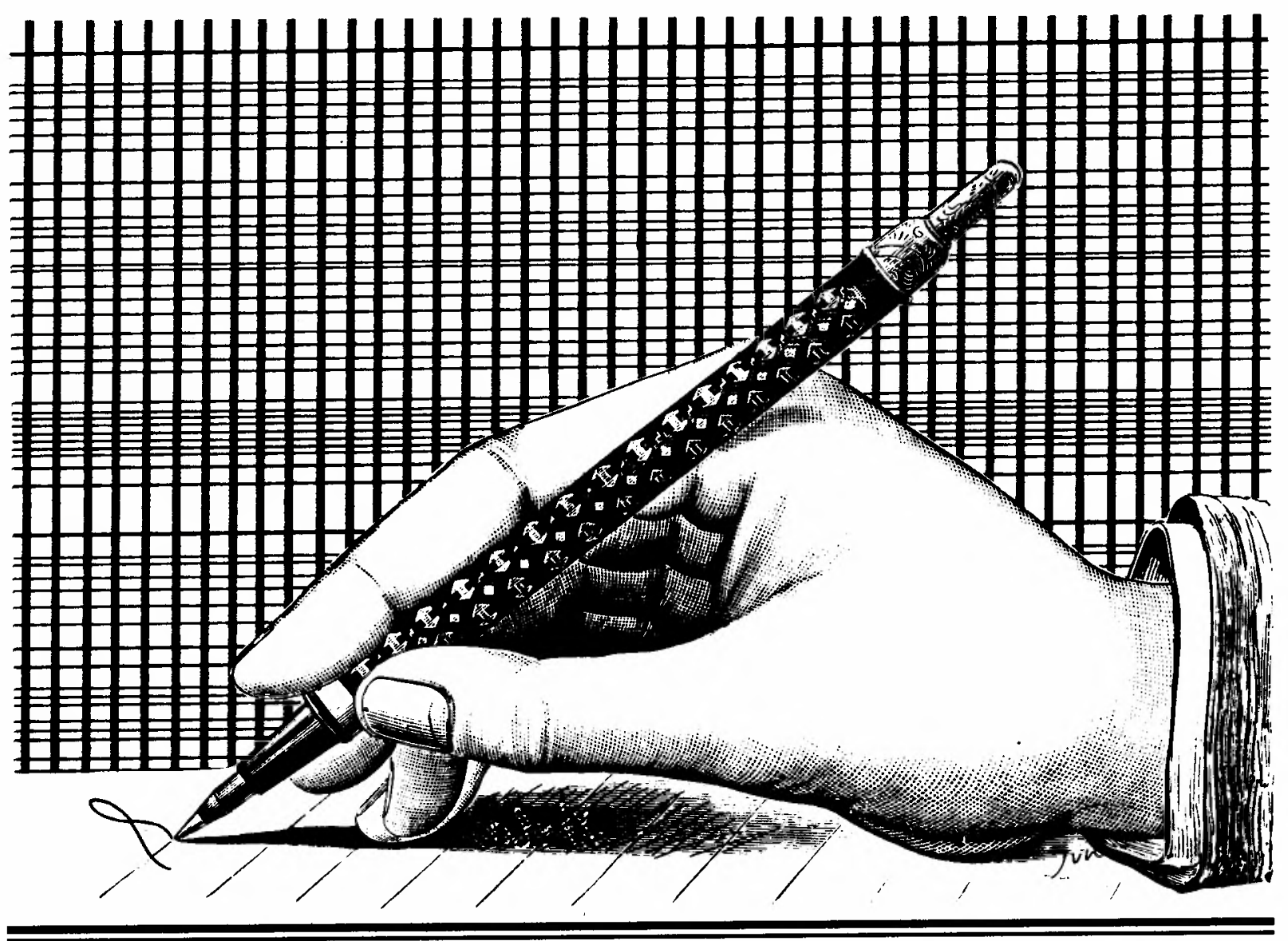

\title{
O PRINCÍPIO CONSTITUCIONAL DA ESTRITA LEGALIDADE E O PARECER NORMATIVO CST № 46, DE 17.08.87
}

- WALDIR LUR BRAGa

Mestre em Direito Tributário e Professor de Direito Tributário da EAESP-FGV.

\section{INTRODUÇÃO}

A ludindo a determinado caso que alega conA creto, a Coordenação do Sistema de Tributação, do Ministério da Fazenda, recentemente exarou o Parecer Normativo CST $n^{2} 46$, de 17.08.87, cujo item 2 se encontra assim redigido:

"2. Em caso concreto, foi identificada transação em que certa pessoa jurídica $A$ domiciliada no pais, com capital inteiramente pertencente a grupo sediado no exterior, constituiu a sociedade $B$ mediante cisāo parcial de seu patrimônio, mantendo-se nas sociedades $A$ e $B$ a mesma participação acionária dos investidores estrangeiros. Posteriormente, a empresa cindida $A$ adquiriu dos acionistas alienigenas (também seus próprios acionistas) parcela do capital da empresa $B$, pretendendo remeter para o exterior o valor da transação, a título de retorno de capital, com o que não haveria incidência do imposto de renda."

E no item 6, acha-se a conclusão oficial, redigida nos seguintes termos:

"6. Em face do objetivo do artigo 51 da Lei $n^{\circ}$ $7.450 / 85$ e de seus próprios termos, a realização de operações simuladas com o fito de elidir o surgimento da obrigação tributária principal ou de gerar maiores vantagens do que as proporcionadas pela lei fiscal, não deve inibir a aplicação de hipóteses de incidência do imposto de renda sobre a aquisição de disponibilidade econômica oujuridica de rendimentos e ganhos de capital. Essas operações não podem ser aceitas para legitimar conseqüências tributárias, visto que são procedimentos legais apenas no seu aspecto for- 
mal, mas ilícitas na medida em que pretendem encobrir ato de natureza jurídica com efeitos tributários mais onerosos para o contribuinte; por isso mesmo, devem prevalecer os efeitos tributários do negócio dissimulado, ao revés daquelés decorrentes do ato jurídico formalizado apenas para gerar conseqüências entre as partes."

Pois bem. A Coordenação do Sistema de Tributação, sob a alegação de simulação e por intermédio do Parecer Normativo em questão, atribuiu ao retorno de capital ao exterior os mesmos efeitos da distribuição de lucros (incidência do IRF à alíquota de $25 \%$ ).

Desconhecemos o caso alegadamente concreto, de forma que especificamente sobre ele não podemos opinar. Todavia, partindo das premissas colocadas a público (item 2 do Parecer Normativo), não podemos, de modo algum, concordar com a conclusão a que chegou a já referida Coordenação do Sistema de Tributação. E é com base apenas nessas premissas que iremos opinar.

\section{NOSSOS COMENTÁRIOS}

\section{PRINCÍPIO CONSTITUCIONAL DA ESTRITA LEGALIDADE}

Estabelece o artigo 153, § $2^{2}$, da Constituição da República, que:

"Ninguém será obrigado a fazer ou deixar de fazer alguma coisa senão em virtude de lei."

Está aí consagrado, a nível constitucional, o princípio de legalidade, pelo qual somente a lei com exclusão de quaisquer atos administrativos, tais como decretos, portarias ministeriais, etc. pode determinar que alguém (aí incluídas as pessoas jurídicas, além das pessoas naturais) proceda ou deixe de proceder desta ou daquela maneira.

ROQUE ANTONIO CARRAZZA, a respeito do princípio em foco, ensina que:

"Bastaria este dispositivo constitucional para que tranqüilamente pudéssemos afirmar que, no Brasil, ninguém pode ser obrigado a pagar um tributo ou cumprir um dever instrumental tributário, que não tenham sido criados por meio de lei, da pessoa política competente, é óbvio. Dito de outro modo, do princípio expresso da legalidade poderíamos extratar o princípio da legalidade tributária."(1)

Consoante 0 ensinamento de Carrazza, o princípio da legalidade, contido no dispositivo constitucional supratranscrito, seria bastante e suficiente para vincular, à lei, a criação e a cobrança de tributos. Não obstante isso, o legisla- dor constituinte, visando a dar maior proteção ao contribuinte, não se contentou em submeter a tributação ao já várias vezes aludido princípio da legalidade, o qual se espraia sobre todo e qualquer ramo do Direito (Civil, Penal, Comercial, Tributário, etc.); muito pelo contrário, fez o legislador constituinte absoluta questão de inserir na Constituição da República duas outras disposições sobre legalidade, só que estas para aplicação específica ao ramo tributário. A primeira encontra- se no capítulo concernente ao Sistema Tributário, e acha-se assim redigida:

"Artigo 19 - É vedado à União, aos Estados, ao Distrito Federal e aos Municípios:

I - Instituir ou aumentar tributo sem que a lei o estabeleça..." (grifo nosso)

A segunda, por stua vez, ocupa lugar no capítulo reservado aos direitos e garantias individuais, apresentando-se nos seguintes termos:

"Artigo 153...

$\$ 29$ - Nenhum tributo será exigido ou aumentado sem que a lei o estabeleça..." (grifo nosso)

Tendo em vista essas duas disposições constitucionais, complementa CARRAZZA ensinando que:

"Não é por outro motivo que se tem sustentado que em nosso ordenamento jurídico vige, mais do que o princípio da legalidade tributária, o princípio da estrita legalidade. "(2)

De fato, a preocupação no sentido de proteger o contribuinte contra eventuais arroubos do Fisco (como no caso do PN $n^{2} 46 / 87$ ) levou o legislador constituinte a imprimir maior severidade ao princípio da legalidade quando operante na órbita do Direito Tributário. Surge, então, o princípio da estrita legalidade da tributação.

O princípio em questão não se contém nos quadrantes da Constituição; inversamente como, aliás, não poderia deixar de ser -, espalhase por todo o ordenamento, sendo inclusive encontrado na própria definição de tributo, constante do Artigo $3^{2}$ do Código Tributário Nacional (CTN), conforme adiante demonstraremos.

Enfim, nullum tributum sine lege.

\section{PRINCÍPIO CONSTITUCIONAL DA COMPETÊNCIA TRIBUTTÁRIA}

1. CARRAZZA, Roque Antonio. Princípios Constitucionais Tributários e Competência Tributária. Sảo Paulo, Editora Revista dos Tribunais, 1986, p. 96. (grifos nossos)

2. Idem, ibidem, p. 97. (grifos do original) 


\section{Diz AIRES FERNANDINO BARRETO que:}

"Sem dissensōes, se tem aceito, ao longo do tempo, que a Constituição não cria tributos." ${ }^{\text {(3) }}$

É cediço, pois, na doutrina, que a Constituição não institui tributos, mas apenas discrimina (no sentido de distribuir entre) as competências para a sua instituição entre a União, os Estados e os Municipios.

Pois bem. Dentro desse contexto e conforme facilmente se depreende do artigo 21, IV, da Constituição da República, é da União Federal a competência para instituir o imposto de renda.

Mas o que vem a ser, afinal, competência tributária?

ROQUE ANTONIO CARRAZZA, com a mestria que lhe é característica, responde nos seguintes termos:

"Competência tributária é a aptidão para criar tributos, descrevendo (ou alterando), por meio de lei (no caso, ordinária), seus elementos essenciais (hipótese de incidência, sujeito ativo, sujeito passivo, base de cálculo e alíquota). Noutro dizer, é a habilitação, a faculdade potencial, que a Constituição confere a determinadas pessoas, para que tributem."(4)

Desse modo, a União Federal tem a faculdade de, acatados os parâmetros constitucionais, criar o imposto de renda, mediante descrição legislativa (lei) da hipótese de incidência do mesmo.

Com base nas preciosas lições de GERALDO ATALIBA $^{(5)}$, podemos definir hipótese de incidência como sendo a descrição legal de um fato qualquer, lícito, do mundo físico (prestar serviços, importar mercadorias, etc.). Hipótese de incidência é, pois, a descrição genérica e abstrata que a lei faz de um fato qualquer; é, em outras palavras, a conceituação legal de um fato. $O$ legislador, tendo diante de si a realidade fática, identifica certos fatos e descreve-os legislativamente, criando, assim, a hipótese; quando fato previsto genérica e abstratamente verificar-se no mundo-físico, surgirão os efeitos jurídicos (nascimento da obrigação tributária). A previsão legal dá-se o nome, conforme já dito, de hipótese de incidência e ao fato concretamente acontecido, fato imponível. É bom anotar que a doutrina tradicional costuma desacertadamente designar essas duas realidades (hipótese e fato) indistintamente de fato gerador.

Assim, quando da ocorrência, no mundo real, do fato previsto pela hipótese de incidência, nascerá a obrigação tributária (o tributo). Mas, ressalte-se, a obrigação somente nasce se o fato concretamente ocorrido corresponder integralmente àquele contemplado pela hipótese. Em não se verificando, outrossim, integral cor- respondência, a obrigação tributária não surgirá, ainda que o fato ocorrido apresente os mesmos efeitos daquele hipoteticamente previsto.

Prosseguindo. Dentre os aspectos da hipótese de incidência destaca-se, para fins didáticos, 0 aspecto material, no qual encontramos a descrição do fato que, se e quando acontecido, fará surgir a obrigação tributária (o tributo). Tal descrição, ressalte-se desde já, deve ser feita de modo preciso, minucioso mesmo, jamais de maneira genérica, aberta. E assim deve ser por imposição do princípio da estrita legalidade, que, moldando o princípio da competếncia tributária, exige a minuciosa descrição do fato com o intuito de afastar a aplicação da vontade unilateral da autoridade administrativa.

Competência tributária, pois, é a aptidão para criar tributo, descrevendo legislativamente seus elementos essenciais, quais sejam, hipótese de incidência, sujeito ativo, sujeito passivo, base de cálculo e alíquota(6).

Dentre os elementos essenciais importa, para os efeitos específicos deste parecer, a hipótese de incidência, mais precisamente o aspecto material da mesma. Por essa razão, não nos alongamos em considerações sobre os demais elementos.

3. O PRINCÍPIO DA TIPICIDADE DA TRIBUTAÇÃO E O ARTIGO 51 DA LEI N².450, DE 23.12.85

O malsinado artigo 51 da Lei $n^{2} 7.450$, de 23.12.85, estipula que:

"Artigo 51 - Ficam compreendidos na incidência do imposto de renda todos os ganhos $e$ rendimentos de capital, qualquer que seja a denominação que lhes seja dada, independentemente da natureza, da espécie, ou da existência de título ou contrato escrito, bastando que decorram de ato ou negócio que, pela sua finalidade, tenha os mesmos efeitos do previsto na norma específica de incidência do imposto de renda."

Nenhuma dúvida há quanto à competência da União para instituir o imposto de renda; também nenhuma dúvida há sobre o status de lei do supratranscrito artigo 51.

3. BARRETO, Aires Fernandino. Base de Cálculo, Alíquota e Princípios Constitucionais. São Paulo, Editora Revista dos Tribunais, 1987, p. 25. 147

4. CARRAZZA, Roque Antonio. Op. cit. pp. 146-

5. ATALIBA, Geraldo. Hipótese de Incidência Tributária. São Paulo, Editora Revista dos Tribunais, 1978 , p. 56 e seguintes.

6. CARRAZZA, Roque Antonio. Op. cit. 
Em sendo assim, não estariam atendidos os princípios constitucionais da estrita legalidade da competência tributária?

Não. Absolutamente não.

É que nas dobras do princípio da estrita legalidade - que molda inclusive o princípio da competência tributária - encontramos um outro princípio (implícito), qual seja, o princípio da tipicidade da tributação.

Segundo tal princípio, o fato previsto pela hipótese de incidência e que, se e quando acontecido no mundo real, dá nascimento à obrigação tributária (ao tributo) deve ser precisa e minuciosamente descrito pelo legislador, conforme, aliás, deixamos antever no item anterior. O fato deve ser tipificado e caracterizado pela lei.

Efetivamente, descrição genérica, abrangente, implicaria irremediável afronta ao princípio da estrita legalidade, pois conferiria à autoridade administrativa o poder de dizer quando o tributo seria ou não seria devido. Recorde-se, por importante, que ninguém é obrigado a fazer ou deixar de fazer alguma coisa senão em virtude de lei, e não em virtude da vontade da autoridade administrativa. Recorde-se, ainda, que o tributo deve ser cobrado mediante atividade administrativa plenamente vinculada (artigo $3^{\circ}$ do CTN), plenamente vinculada à lei, excluída toda e qualquer possibilidade de a autoridade ir além ou ficar aquém da lei.

ALBERTO XAVIER, sobre o tema, escreve:

"A tipicidade repele assim a tributação baseada num conceito geral ou cláusula geral de tributo, ainda que referido à idéia de capacidade econômica, da mesma forma que em Direito Criminal não é possivel a incriminação com base num conceito ou cláusula geral de Crime."(7)

E, em outro trecho, acrescenta o renomado jurista:

"O método da cláusula geral - tão cara aos Estados totalitários - não pode deixar de brigar com a própria essência do Estado de Direito $e$, em especial, com os valores da segurança jurídica que esta encarna. Em boa verdade ao Estado de Direito repugna a célebre declaração do governo soviético de Munique, em 1919: Toda a ofensa aos princípios revolucionários será punida. A determinação da natureza da pena cabe à live discrição do Juiz."(8)

Assim, estava o cidadão à mercê do Juiz, que podia considerar ofensa aos princípios revolucionários toda e qualquer atitude. Insegurança total, portanto.

A declaração soviética, ao que parece, serviu de inspiração para a redação do artigo 51. De fato, tal dispositivo pode ser assim resumido: ficam compreendidos na incidência do imposto de renda todos os ganhos e rendimentos de capital, conforme a vontade da autoridade administrativa.

Mas, ao que consta, não estamos num Estado totalitário, tampouco soviético (ou estamos?!). Conseqüentemente, não há como se considerar constitucional o aludido artigo 51 .

Na mesma linha que XAVIER, opina o não menos festejado e renomado jurista AIRES FERNANDINO BARRETO. São suas palavras:

"... o princípio da legalidade assume conteúdo rígido $e$ estreitissimo, manifestado através de novo principio contido em suas dobras: o da tipicidade da tributação, que haverá de ser obseroado na criaça e aumento de tributo.

Impoe esse princípio que o tributo tenha a sua hipótese de incidência definida exclusivamente em lei, encerrando, assim, a construção do que se tem denominado de tipo normativo ou tipo tributário.

Esse modelo legal é cerrado, fechado, não ensejando dilargamento pelo aplicador da lei, o que confere a preservação das garantias $e$ direitos prestigiados pela Constituição.

Não basta, no Direito Tributário, a razoável equivalência entre o fato e a hipótese legal caracterizadora dos modelos abertos;exige-se, rigorosamente, o preciso amoldamento do fato ao tipo legalmente definido." ${ }^{(9)}$ (grifos do original)

O já citado artigo 51 busca alcançar os ganhos e rendimentos decorrentes de ato ou negócio que, pela sua finalidade, tenham os mesmos efeitos do previsto na norma específica de incidência do imposto de renda.

$O$ aludido artigo confessa, assim, escancaradamente, que seu objetivo é alcançar fatos (que chama de ato ou negócio) não tipificados pela lei, mas que produzem efeitos iguais aos produzidos por outros fatos legalmente tipificados. Em sendo assim e tendo em vista tudo o que acima foi exposto, especialmente as lições de XAVIER E BARRETO, podemos afirmar, com convicção, que o já inúmeras vezes citado artigo 51 é absoluta e irremediavelmente inconstitucional. E a nossa convicção decorre também das lições de ARY OSWALDO MATTOS FILHO e ROBERTO QUIROGA MOSQUEIRA ${ }^{(10)}$ e J. A. LIMA GONÇALVES ${ }^{(11)}$, juristas que já teceram consideraçð̃es sobre 0 artigo 51.

7. XAVIER, Alberto. Os Principios da Legalidade e da Tipicidade Cerrada da Tributação. Săo Paulo, Editora Revista dos Tribunais, 1978, pp. 83-85.

8. Idem, ibidem, idem.

9. BARRETO, Aires Fernandino. Op. cit., p. 100. (grifos do original) 
ARY OSWALDO MATTOS FILHO, Professor Titular da Cadeira de Direito Tributário da Escola de Administração de Empresas da Fundação Getúlio Vargas, e ROBERTO QUIROGA MOSQUEIRA afirmam:

"Diante de norma tão ampla e genérica, qualquer operação realizada pelos individuos que, por uma abstração, produza efeitos idênticos às operações para as quais já exista norma específica de incidência do imposto de renda, estaria compreendida dentro do campo de incidência desse imposto.

Entendemos que o referido dispositivo $\dot{e}$ inconstitucional quando aplicado inadequadamente, pois tal técnica legislativa é contrária aos princípios que regem o Sistema Tributário Brasileiro, uma vez que para se criar tributo mister se faz descrever toda sua hipótese de incidência, base de cálculo, aliquota, sujeito ativo $e$ dar os critérios de identificação do sujeito passioo da relação jurídica tributária."(12)

E J. A. LIMA GONÇALVES, que produziu excelente estudo sobre o dispositivo legal em análise, conclui:

"Somos, pois, pela evidente e cristalina inaplicabilidade do artigo 51 da Lei Federal $n^{2}$ $7.450 / 85$, por vício de inconstitucionalidade consistente na descrição incompleta da regra matriz de incidência tributária que pretendeu veicuLar." (13)

Não precisamos nos estender mais, bastando afirmar, mais uma vez, a inconstitucionalidade do artigo 51 da Lei $n^{2} 7.450 / 85$.

\section{O PARECER NORMATIVO CST $n^{2} 46$, DE} 17.08.87

a. Cobrança de Tributos - Atividade Administrativa Vinculada

Conforme já tivemos oportunidade de expor, o princípio da estrita legalidade desdobra-se inclusive na definição de tributo, constante do artigo $3^{\circ}$ do Código Tributário Nacional:

"Artigo $3^{9}$ - Tributo é toda prestação pecuniária compulsória, em moeda ou cujo valor nela se possa exprimir, que não constitua sanção de ato ilícito, instituída em Lei e cobrada mediante atividade administrativa plenamente vinculada." (grifo nosso)

Neste ponto, apresenta-se de vital importância a análise da cláusula cobrada mediante atividade administrativa plenamente vinculada.

Os atos administrativos, quais sejam, os atos editados pelas autoridades administrativas (au- toridades ligadas ao Poder Executivo), dividemse em atos vinculados e atos discricionários. Ato vinculado é aquele integralmente submetido à lei, de modo que a autoridade administrativa, ao expedi-lo, não pode ir além ou ficar aquém da lei, devendo, isto sim, observar fielmente todas as minúcias previstas pela lei. Ato discricionário, por seu turno, é aquele que possibilita à autoridade administrativa, por força da própria lei, certa liberdade de escolha, segundo critérios de conveniência e oportunidade.

CELSO ANTONIO BANDEIRA DE MELLO, festejado administrativista, ensina que:

" $A$ diferença nuclear entre ambos residiria em que, nos primeiros (vinculados), a administração não dispõe de liberdade alguma, posto que a lei já regulou antecipadamente em todos os aspectos o comportamento a ser adotado, enquanto nos segundos (discricionários) a disciplina legal deixa ao administrador certa liberdade para decidir-se em face das circunstâncias concretas do caso, impondo-lhe e simultaneamente facultando-lhe a utilização de critérios próprios para avaliar ou decidir quanto ao que lhe pareça ser o melhor meio de satisfazer ao interesse público que a norma legal visa realizar. "(14)

Desse modo, na cobrança de tributos, as autoridades administrativas devem ater-se aos estritos termos da lei, não podendo cobrar mais, nem menos; igualmente, não podem impor condições, obrigações, prazos, etc., que não tenham sido legalmente estabelecidos (atividade administrativa plenamente vinculada).

\section{b. A Função dos Pareceres Normativos}

Hierarquicamente, abaixo das leis, que criam os tributos, temos os decretos, que são atos baixados pelo Presidente da República.

Os decretos limitam-se a prover a fiel execução das leis, subordinando-se integralmente a elas. Com efeito, dispõe o artigo 81, III, da Constituição da República, que:

10. MATTOS FILHO, Ary Oswaldo e MOSQUEIRA, Roberto Quiroga. "Imposto de Renda - Tributação das Operaçóes com Ouro e Outras Commodities". In CEFIR n 233, 1986.

11. GONCALVES, J.A.Lima. "O Artigo 51 da Lei Federal $n^{2} 7.450 / 85$ e o Sistema Constitucional Tributário Brasileiro". In: Revista de Direito Tributário $\mathrm{n}^{2} 35$, jan/mar., 1986.

12. MATTOS FILHO, Ary Oswaldo e MOSQUEIRA, Roberto Quiroga. Op. cit., p. 26.

13. GONÇALVES, J.A. Lima. Op. cit., p. 255.

14. MELLO, Celso Antonio Bandeira de. Elementos de Direito Administrativo. Såo Paulo, Editora Revista dos Tribunais, 1984, p. 61. (parênteses nossos) 


\author{
"Artigo 81. Compete privativamente ao Presi- \\ dente da República:
}

III - sancionar, promulgar e fazer publicar as leis, expedir decretos e regulamentos para sua fiel execução. "(grifo nosso)

O dispositivo constitucional acima desdobrase no artigo 99 do CTN, segundo o qual:

"Artigo 99 - O conteúdo e o alcance dos decretos restringem-se aos das leis em função das quais sejam expedidos..."

Seguindo. Por força do princípio constitucional da estrita legalidade, que se reflete inclusive no artigo 81, III, acima transcrito, o decreto não pode instituir obrigações acessórias, descrever infrações ou impor quaisquer encargos que possam vir a repercutir na liberdade ou no patrimônio das pessoas. Verifica-se, assim, que é bastante restrito o campo de atuação do decreto, mesmo quando baixado pelo Presidente da República, autoridade máxima do Poder Executivo.

E quanto aos Pareceres Normativos?

Ora, se ninguém é obrigado a fazer ou deixar de fazer alguma coisa senão em virtude de lei, se os tributos somente podem ser criados e sua cobrança disciplinada apenas por lei, se o tributo deve ser cobrado mediante atividade administrativa plenamente vinculada e se o decreto, que é baixado pelo Presidente da República, tem um campo de atuação muito restrito, pouco resta ao Parecer Normativo.

O Parecer Normativo representa única e exclusivamente a opinião do Fisco sobre determinada disposição legal, tendo o mesmo valor jurídico que a opinião do contribuinte. Como se sabe, na relação jurídico-tributária, que se instaura com a ocorrência do fato imponivel e que dá nascimento ao tributo, não há relação de inferioridade-superioridade, de forma que o sujeito ativo (Fisco) e o sujeito passivo (Contribuinte) se situam no mesmo patamar. Ambos se subordinam unicamente à lei.

Se, por um lado, é louvável o Parecer Normativo que esclarece o contribuinte leigo em $\mathrm{Di}$ reito Tributário, por outro lado, é indesejável o que vai além do que dispõe a lei que visa a interpretar.

O Parecer Normativo não pode inovar no Direito Tributário (pois isto é tarefa da lei), de modo que não pode criar ou dispensar obrigações, fixar prazos ou condições, etc., que não estejam previstos em lei. Caso disponha além (ou aquém) da lei, será irremediavelmente ilegal e/ou inconstitucional.

O Parecer Normativo pode única e tãosomente tornar explícito o que está implícito na lei, tornar mais acessíveis ao contribuinte leigo as disposições legais, nem sempre de fácil interpretação. Enquanto contido dentro desses quadrantes, é louvável e colabora com o contribuinte; caso exceda os limites legais, é ilegal e/ ou inconstitucional.

Por outro lado, o Parecer Normativo obriga somente os senhores Auditores Fiscais do Tesouro Nacional (e outros funcionários públicos), pois estes, por razões de hierarquia, devem obediência à Autoridade que aprova o Parecer e manda que seja observado. Contudo, se o Parecer Normativo for manifestamente ilegal, os senhores Auditores Fiscais não estão obrigados (ou melhor, não devem) a obedecê-lo, sob pena de serem coresponsáveis com a autoridade superior que o expediu.

Mas o contribuinte de forma alguma está obrigado a obedecer às disposições constantes de Parecer Normativo algum, pois só é obrigado a fazer ou deixar de fazer alguma coisa em virtude de lei.

c. O Parecer Normativo 46/87 e o Artigo 51 da Lei $n^{2} 7.450 / 85$

Consoante acima demonstrado, os pareceres normativos, assim como todos os demais atos administrativos, devem fidelíssima obediência à lei.

O Parecer Normativo 46/87 não foge à regra. Ocorre, todavia, que tal Parecer foi editado tendo como base legal o artigo 51 da Lei $n^{2} 7.450 / 85$, o qual, como visto anteriormente, é absolutamente inconstitucional.

De conseguinte, o Parecer em questão carece de fundamento legal, não podendo, portanto, ser reputado juridicamente válido.

d. O Parecer Normativo CST ne 46/87 e o Princípio Constitucional da Estrita Legalidade

O Parecer Normativo em questão não poderia ser reputado válido, independentemente da inconstitucionalidade do artigo 51 da Lei $n^{2}$ $7.450 / 85$, já que versa sobre operações simuladas?

A resposta é pela negativa, uma vez que o $\mathrm{Pa}$ recer não versa sobre operações simuladas, mas, isto sim, considera simuladas as operações que, embora praticadas consoante a lei, implicam em menor carga tributária para o contribuinte. Recorde-se que o item 6 do aludido Parecer diz que:

"Essas operações não podem ser aceitas para legitimar consequiências tributárias, visto que são procedimentos legais apenas no seu aspecto formal, mas ilícitas na medida em que pretendem encobrir ato de natureza jurídica 
com efeitos tributários mais onerosos para 0 contribuinte..."

Assim, nos termos do Parecer, são pura e simplesmente simuladas e por isso ilícitas todas as operações que conduzem o contribuinte por um caminho menos oneroso em termos tributários.

Nada mais abusado. Nada mais inaceitável. O artigo 51, mais recatado, limitou-se a ampliar a incidência do imposto de renda às operações que, embora não expressamente previstas pela legislação, apresentam os mesmos efeitos daquelas previstas. E exatamente por isso, por ter criado uma cláusula geral, é inconstitucional. $\mathrm{O} \mathrm{Pa}-$ recer, porém, foi mais além, acusando de simuladas e por isso ilícitas tais operações, mesmo sem qualquer análise preliminar por parte da fiscalização. $O$ Parecer não pode prosperar.

Com efeito, dispõe o artigo 102 do Código Civil que:

"Artigo 102 - Haverá simulação nos atos jurídicos em geral:

I - Quando aparentarem conferir ou transmitir direitos a pessoas diversas das a quem, realmente, se conferem, ou transmitem.

II - Quando contiverem declaração, confissão, condição, ou cláusula não verdadeira.

III - Quando os instrumentos particulares forem antedatados ou pós-datados."

E complementa o artigo 105 estabelecendo que:

"Artigo 105 - Poderão demandar a nulidade dos atos simulados os terceiros lesados pela simulação, ou os representantes do poder público, a bem da lei, ou da fazenda."

Em se tratando de operação efetivamente simulada, nos termos acima, não pode, é certo, produzir os efeitos tributários pretendidos. $\mathrm{E}$ isto pela simples razão de tais efeitos decorrerem de uma operação simulada.

Mas, por outro lado, a operação que conduz o contribuinte por uma trilha mais suave em termos tributários absoluta e definitivamente não constitui uma operação simulada.

Com efeito, nada impede que o contribuinte deixe de lado uma fórmula legal, que leva a efeitos tributários mais onerosos, e parta para outra fórmula legal, mais favorável. Por quê? Porque no Direito Tributário vigora o princípio da tipicidade da tributação, pelo qual somente se sujeitam ao tributo as operações tipificadas, especificadas, identificadas pela lei. Aplicam-se, aqui, os comentários contidos no item III, acima.

Desde que a fórmula escolhida pelo contri- buinte encontre respaldo na lei, os efeitos tributários serão os próprios dessa fórmula, independentemente de esses mesmos efeitos revelarem-se favoráveis ou desfavoráveis ao Fisco. Se a fórmula utilizada pelo contribuinte revelar-se desfavorável ao Fisco, poderá ele sugerir ao Presidente da República (no âmbito federal) que encaminhe à apreciação do Congresso Nacional projeto de lei inserindo a aludida fórmula dentre as alcançadas pelo imposto de renda. Nada mais pode fazer, pois, se o fizer, incorrerá em inafastável ilegalidade.

Em face do exposto, fica fácil concluir que o Parecer Normativo CST $n^{2} 46 / 87$ não pode ser reputado válido mesmo quando isolado do artigo 51 da Lei $\mathbf{n}^{8} 7.450 / 85$, pois não trata de operações simuladas, mas, sim, atribui essa qualidade a operações favoráveis aos contribuintes em termos de carga fiscal.

e. A Operação Realizada pela Sociedade A

Conforme se depreende do item 2, do Parecer Normativo CST $n^{8} 46 / 87$, a Sociedade A, ao invés de remeter lucros aos seus acionistas no exterior, adquiriu parte do capital da Sociedade B (pertencente aos mesmos acionistas de A) e fez a remessa a título de retorno de capital (pagamento do preço das ações), remessa essa não sujeita, nos termos da legislação vigente, à incidência do imposto de renda na fonte.

A compra de uma sociedade por outra, com o conseqüente pagamento do preço aos acionistas, ainda que domiciliados no exterior, constitui operação que encontra expresso amparo nas legislações comercial, civil e tributária. Não se trata, obviamente, de uma criação da sociedade A. Assim, agiu a sociedade A dentro dos quadrantes legais.

Mas não estaria essa operação apenas coberta com um manto de legalidade, nos termos do $\mathrm{Pa}$ recer 46? Não constituiria, no fundo, mera operação simulada e por isso ilícita, já que redunda em menor carga tributária?

A resposta é não!

Com efeito, duas opções se apresentaram à Sociedade A: a primeira, pura e simplesmente distribuir lucros aos seus acionistas, reter e recolher o correspondente IRF; a segunda, adquirir a Sociedade B e efetuar a remessa ao exterior a título de retorno de capital, remessa essa não sujeita ao IRF.

Quanto à primeira opção, não há o que se comentar; quanto à segunda, é também absolutamente legal e não apenas - na linguagem do $\mathrm{Pa}-$ recer - coberta com um manto de legalidade. Nada obsta, é certo, a compra da Sociedade B pela A e a remessa do preço aos respectivos acionistas no estrangeiro. Nisso não há nenhuma 
simulação, pois, também, é certo, a compra de uma Sociedade é feita através de instrumentos que seguem uma praxe legal e que são devidamente arquivados na Junta Comercial e, em se tratando de investimento estrangeiro, há ainda as formalidades junto ao Banco Central.

Ambas as operações (distribuição de lucros e retorno de capital) são típicas, sendo que devem ocorrer, na órbita tributária, os efeitos típicos da opção feita.

A distribuição de lucros é uma operação prevista pela legislação do imposto de renda; portanto, uma operação típica, geradora de determinados efeitos tributários. Conseqüentemente, as operações que, nos termos da lei, não tiverem essa natureza não produzirão os efeitos próprios da distribuição de lucros.

O pagamento efetuado pela compra das ações de uma sociedade não se confunde com distribuição de lucros. Por conseguinte, não produz os efeitos tributários típicos da distribuição de lucros (incidência do IRF).

Não pode o Fisco, sob a frágil alegação de estar sendo prejudicado, imputar ao pagamento do preço de ações os efeitos da distribuição de lucros. Se o fizer - como de fato o fez - incorrerá em inafastável ilegalidade/inconstitucionalidade.

\section{CONCLUSÕES}

a. No Brasil vigora, em toda sua plenitude, o princípio da legalidade, pelo qual ninguém é obrigado a fazer ou deixar de fazer alguma coisa senão em virtude de lei.

b. No âmbito tributário, esse princípio é ainda mais severo, sendo denominado de princípio da estrita legalidade.

c. O princípio da estrita legalidade, moldando o princípio da competência tributária, impede que a União, Estados e Municípios criem tributos mediante a chamada "cláusula geral"; pelo contrário, impõe a plena tipificação dos fatos que, se e quando acontecidos no mundo real, darão nascimento à obrigação tributária (ao tributo).

d. Do princípio da estrita legalidade e do princípio da competência tributária, este moldado na forma acima, decorre o príncípio da tipicidade da tributação.

e. É da União Federal a competência para instituir e cobrar o imposto de renda. Constitui requisito impostergável para o exercício dessa competência a descrição minuciosa do fato que fará surgir a obrigação tributária.

f. $O$ artigo 51 da Lei $\mathrm{n}^{\mathbf{2}} 7.450 / 85$, mediante "cláusula geral", procura alcançar todos os atos ou negócios que, pelas suas finalidades, apresen- tem os mesmos efeitos dos atos ou negócios previstos especificamente (tipificados) pela legislação do imposto de renda. Justamente por isso, por não tipificar os atos ou negócios que procura abranger, é irremediavelmente inconstitucional.

g. A cobrança de todo e qualquer tributo, por exigência do princípio da estrita legalidade, deve ser efetuada mediante atividade administrativa plenamente vinculada. Por conseguinte, não pode a autoridade administrativa, seja ela qual for, ir além ou ficar aquém da lei, podendo, única e exclusivamente, explicitar o que se acha implícito na lei. Nenhum ato administrativo pode ser editado sem que tenha base na lei.

h. O Parecer Normativo CST $n^{2} 46 / 87$ foi editado com base no artigo 51 da Lei $n^{2} 7.450 / 85$; tendo em vista a patente inconstitucionalidade do aludido dispositivo legal, o Parecer deixa de apresentar qualquer validade no mundo jurídico.

i. Independentemente do artigo 51, o Parecer Normativo em questão poderia apresentar efeitos meramente declaratórios, caso tratasse de operações efetivamente simuladas.

j. No entanto, longe de tratar de operações efetivamente simuladas, o Parecer Normativo em questão considera simuladas todas os operações que conduzem o contribuinte por um caminho tributário menos oneroso. E, assim, voltamos ao já referido artigo 51 que, por inconstitucional, retira do Parecer Normativo qualquer validade jurídica.

k. Operações simuladas são aquelas que apresentam os vícios indicados pelo artigo 102 do. Código Civil e devem, necessariamente, ser provadas pelo Fisco. As operações praticadas com observância dos ditames legais são lícitas, independentemente de acarretarem efeitos favoráveis ou desfavoráveis ao Fisco.

1. O contribuinte não é obrigado a trilhar caminho que lhe seja mais oneroso, mais favorável ao Fisco. $\mathrm{O}$ contribuinte é obrigado, isto sim, a recolher o imposto correspondente ao ato ou negócio que praticar e que esteja previsto pela lei (hipótese de incidência) como apto a dar origem à obrigação tributária. Se o contribuinte praticar outro ato ou negócio, ficará sujeito às conseqüências desse outro ato ou negócio, que poderão ser mais ou menos favoráveis em termos tributários (tipicidade da tributaçăo). A escolha deste ou daquele ato ou negócio compete única e exclusivamente ao contribuinte, devendo o Fisco se conformar com os efeitos decorrentes da escolha.

m. A astúcia do contribuinte em identificar o melhor caminho não se confunde, de modo algum, com simulação. 